\title{
PENGGUNAAN BIOCHAR DAN PUPUK KANDANG TERHADAP PERTUMBUHAN BIBIT CENGKEH VARIETAS ZANZIBAR
}

The Use Of Biochar And Manure On The Growth Of Clove Seeds Varieties Zanzibar

\author{
Salawati, ${ }^{\text {*) }}$ Firdatul Hasanah, Sjarifuddin Ende, Bustaman, Tony \\ Sekolah Tinggi Ilmu Pertanian Mujahidin Tolitoli \\ *) e-mail: wati.lasandrang@ gmail.com
}

\begin{abstract}
ABSTRAK
Penggunaan tanah sebagai media pertumbuhan bibit cengkeh dihadapkan pada kesuburan tanah yang rendah, sehingga dibutuhkan penambahan pembenah tanah seperti biochar dan pupuk kandang untuk meningkatkan kualitas mediah pembibitan yang mendukung pertumbuhan bibit cengkeh. Penelitian ini bertujuan untuk mengetahui kombinasi biochar dan pupuk kandang pada media tumbuh bibit cengkeh. Penelitian ini telah dilaksanakan di tempat pembibitan kampus 2 STIP Mujahidin Tolitoli pada bulan Januari sampai dengan bulan Juni 2018, menggunakan rancangan acak kelompok faktor tunggal dengan 7 taraf perlakuan. Pengamatan dilakukan pada variabel tinggi tanaman, jumlah daun, panjang akar, diameter batang, berat segar, dan berat kering bibit cengkeh. Hasil penelitian menunjukkan bahwa penggunaan biochar, tanah, pupuk kandang sapi masing masing berbanding $1(\mathrm{v} / \mathrm{v})$ merupakan perlakuan terbaik terhadap parameter tinggi tanaman, jumlah daun, diameter batang, panjang akar berat segar dan berat kering turus bibit cengkeh pada umur 12 minggu setelah tanam.
\end{abstract}

Kata kunci : Biochar, pupuk organik, nursery, Syzygium aromaticum

\section{ABSTRACT}

The use of soil as a growth media for clove seedlings is faced with low soil fertility, so that additional soil enhancers such as biochar and manure are needed to improve the quality of nursery media that support the growth of clove seedlings. This study aims to determine the combination of biochar and manure on growing medium of clove seeds. This research has been carried out at the nursery campus 2 STIP Mujahidin Tolitoli in January to June 2018, using a single factor randomized design with 7 levels of treatment. Observations were made on variable plant height, number of leaves, root length, stem diameter, fresh weight, and dry weight of clove seedlings. The results showed that the use of biochar, soil, cow manure each compared to $1(\mathrm{v} /$ v) was the best treatment of plant height, number of leaves, stem diameter, root length, fresh weight and dry weight of clove seedlings at 12 weeks after planting.

Keywords: Biochar, organic fertilizer, nursery, Syzygium aromaticum

\section{PENDAHULUAN}

Cengkeh (Syzygium aromaticum) merupakan tanaman asli Indonesia yang berasal dari kepulauan Maluku (Randriani \& Syafaruddin, 2011), serta salah satu komoditas penting di Sulawesi Tengah khususya di Kabupaten Tolitoli karena menyumbang pendapatan negara berupa cukai rokok dan pajak serta menyerap tenaga kerja yang seluruhnya merupakan pertanaman rakyat. Produksi cengkeh pada tahun 2016 mencapai 9.077,33 ton, sementara itu luas area tanaman cengkeh mencapai 40.307 
ha yang terdiri dari yang menghasilkan sebanyak 21.689 ha, tanaman tua 4.152 dan tanaman muda sebanyak 14.466 ha (BPS, 2016). Budidaya tanaman cengkeh terus dikembangkan oleh petani karena harga jual meningkat, hal ini akan berhubungan dengan kebutuhan bibit yang unggul. Bertambahnya jumlah tanaman berumur tua sehingga perlu penggantian tanaman serta perluasan areal tanam yang terus bertambah akan membutuhkan bibit cengkeh.

Produksi tanaman cengkeh ditentukan oleh bibit yang sehat dan kuat, bibit yang sehat hanya didapatkan melalui pemeliharaan sewaktu pembibitan kegiatan pembibitan merupakan tahapan awal penanaman yang akan menentukan pertumbuhan dan produksi tanaman cengkeh selanjutnya. Pertumbuhan bibit cengkeh yang sehat membutuhkan kondisi lingkungan tumbuh yang optimal, sehingga bibit yang dihasilkan sehat, ketersediaan dan keseimbangan unsur hara dalam jumlah yang cukup merupakan salah satu faktor penting dalam pertumbuhan tanaman, selain itu bahan organik yang cukup juga berperan penting dalam pertumbuhan tanaman (Wahyudi, 2009). Pemilihan media tanam menjadi salah satu faktor yang menunjang pertumbuhan dan perkembangan bibit, Media pertumbuhan bibit yang digunakan harus bersifat ringan, gembur dan subur, sehingga memungkinkan untuk pertumbuhan bibit, seperti pupuk kandang dan biochar.

Biochar merupakan bahan organik yang telah terdekomposisi secara thermal. Penggunan biochar dapat memperbaiki struktur tanah (Hartatik et al., 2015), memperbaiki permukaan luas koloid, dapat menahan air dan tanah dari erosi (Lehmann, 2007). Meningkatkan ketersediaan P, KTK dan C-organik (Nur, et al, 2014; Rostaliana, et al 2012; Salawati, et al., 2016; Yamato et al., 2006). Menurunkan run-off nitrogen (Gao \& DeLuca, 2016; Knowles et al, 2011). Meningkatkan kapasistas tanah memegang air (Duong et al., 2017; Santi \& Goenadi, 2010; Sutono \& Nurida, 2012) Biochar lebih efektif menahan unsur hara bagi tanaman (Gani, 2009; Laird et al., 2010; Utomo \& Islami, 2016). Aplikasi biochar ke tanah pertanian memberikan manfaat agronomis yang nyata (Asai et al., 2009; Mateus et al., 2017; Sujana, 2014), namun hasil tersebut tidak bersifat universal (Jha et al., 2010). Beberapa hasil penelitian menunjukkan hasil yang berbeda, hal ini disebabkan oleh sifat biochar yang berbeda tergantung bahan dasarnya, sehingga terjadi interaksi yang berbeda antara biochar dan tipe tanah (Glaser et al., 2002; Ogawa et al., 2006). Karena itu masih diperlukan penelitian untuk pengembangan pemanfaatan biochar untuk pembibitan tanaman cengkeh.

Kombinasi media tumbuh tanah, pupuk kandang sapi dan biochar merupakan salah satu alternatif untuk menyediakan unsur hara di dalam tanah. Pupuk kandang berperan sebagai bahan pembenah tanah yang bermanfaat untuk memperbaiki struktur tanah, meningkatkan daya kation, memacu aktivitas mikroba pendaur hara dan pendekomposisi bahan organik dalam tanah. Sedangkan biochar juga mampu mempengaruhi ketersediaan unsur hara memperbaikan kualitas tanah, sifat kimia, dan 
sifat fisik tanah, (Widowati., et al. 2014). Penelitian ini bertujuan untuk mengetahui pengaruh kombinasi biochar terhadap pertumbuhan bibit tanaman cengkeh.

\section{METODE PENELITIAN}

Penelitian ini dilaksanakan di lokasi Pembibitan Kampus 2 STIP Mujahidin Toli-toli Kelurahan Tuweley Kabupaten Tolitoli Provinsi Sulawesi Tengah pada bulan Januari sampai bulan Juni Tahun 2018 pada ketinggian tempat 112 meter dari permukaan laut (mdpl).

Alat yang digunakan pada penelitian ini adalah cangkul, sekop, parang, mistar, timbangan analitik, jangka sorong, oven, martel, selang, kertas label, paranet, balok, alat tulis menulis dan kamera. Adapun Bahan bahan yang digunakan adalah : Benih cengkeh Zanzibar, polybag ukuran 15 x $30 \mathrm{~cm}$, pupuk kandang (Pukan) sapi, tanah, biochar, papan, jaring.

Penelitian ini menggunakan Rancangan Acak Kelompok (RAK) yang terdiri dari 7 taraf perlakuan yaitu :

$\mathrm{P}_{0}=$ Media Tanah ( tanpa pupuk kandang sapi dan biochar), $\mathrm{P}_{1}=1$ Tanah : 1 Pupuk kandang sapi $(1: 1), \mathrm{P}_{2}=1$ Tanah : 1 Biochar $(1: 1), \mathrm{P}_{3}=1$ Tanah : 1 Pupuk kandang Sapi : 1 Biochar $(1: 1: 1), \mathrm{P}_{4}=1$ Tanah : 2 Pupuk kandang Sapi : 1 Biochar (1: $2: 1), \mathrm{P}_{5}=1$ Tanah : 1 Pupuk kandang Sapi : 2 Biochar $(1: 1: 2), \mathrm{P}_{6}=1$ Tanah : 2 Pupuk kandang sapi : 2 Biochar (1:2:2). Masing-masing diulang sebanyak 3 kali, sehingga terdapat 21 unit percobaan. Setiap unit percobaan terdiri dari 5 tanaman jadi dapat diperoleh 105 populasi. serta Jumlah sampel yang diambil setiap perlakuan sebanyak 3 sehingga jumlah sampel keseluruhan yaitu 63 sampel. Data yang diperoleh dianalisis pada sidik ragam. Apabilah terdapat pengaruh nyata, atau sangat nyata pada perlakuan kombinasi media tanam, maka dilakukan uji lanjut dengan menggunakan uji BNJ $5 \%$.

\section{Pelaksanaan Penelitian}

\section{Persiapan biochar}

Pembuatan biochar menggunakan metode gasifikasi atau sumber panas langsung. Tahapan dimulai dari menyiapkan sekam padi, selanjutnya dijemur agar kering merata, lalu dibuat tumpukan menggunung, yang bagian tengahnya dilubangi ditaruh 3 lembar kertas putih sebagai pemantik api, selanjutnya dilakukan pembakaran hingga 2 jam, setelah sekam berwarna hitam, disiram air agar tidak terjadi pengabuan. Alur pembuatan biochar Nampak pada gambar 1 . 



Gambar 1 alur pembuatan biochar metode gasifikasi

\section{Persiapan Bibit}

Sumber benih untuk dijadikan bibit diperoleh dari penangkar muliah sejahtera, dengan ciri berwarna ungu kehitaman mengkilat. Benih yang didapatkan ditimbang untuk menetapkan keseragam berat, lalu dikupas dan direndam, kemudian disemai di polybag serta dirawat hingga umur 3 bulan, untuk selanjutnya dipindahkan ke media pembibitan. Tempat pembibitan dibuat dengan mendirikan naungan yang beratap paranet dengan ukuran tinggi 2 meter, panjang 4 meter serta lebar 3 meter dan dilakukan pembagian jalur polybag secara memanjang sebanyak 3 ulangan. Masing-masing jalur

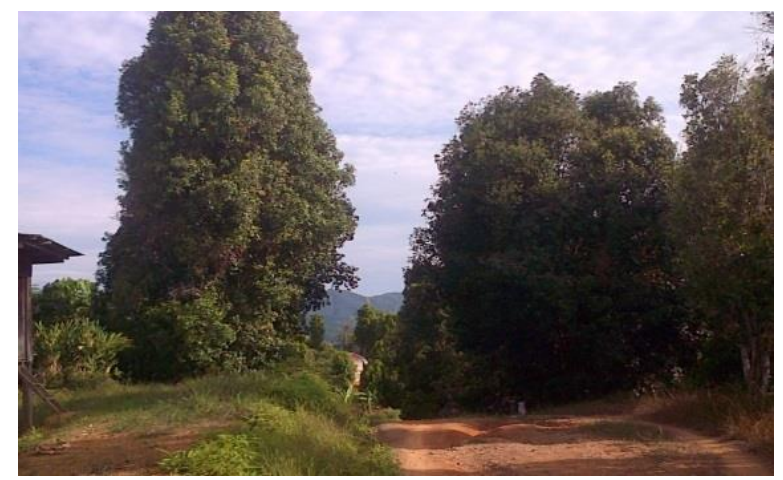

memiliki lebar $100 \mathrm{~cm}$ dan jarak antar perlakuan $30 \mathrm{~cm}$ serta jarak antara ulangan 30 $\mathrm{cm}$. Lokasi pembibitan merupakan tempat yang bersih dari rumput serta dekat dengan sumber air.

Gambar 2 Sumber benih yang dijadikan bibit

Pembuatan media tanam, pengambilan tanah di lakukan di desa Tambun kecamatan Baolan kabupaten Tolitoli, tanah diambil pada kedalaman 0-20 cm dari atas permukaan tanah, selanjutnya tanah dikering udarakan dan diayak dengan ayakan $2 \mathrm{~mm}$. selanjutnya tanah dicampur biochar dan pupuk kandang sapi sesuai kombinasi secara merata (v/v) sesuai perlakuan. Lalu ditimbang sebanyak $3 \mathrm{~kg}$ dan dimasukkan ke dalam polybag yang berukuran $15 \times 30 \mathrm{~cm}$, lalu dilabeli sesuai perlakuan.

\section{Penanaman}

Bibit cengkeh yang telah siap di transplanting (umur 3 bulan) ditanam pada polybag yang telah berisi media sesuai perlakuan. Polybag yang digunakan berukuran $15 \times 30 \mathrm{~cm}$ dan masing-masing berisi satu bibit cengkeh yang diberi lebel sesuai kode perlakuan. 
Pemeliharaan tanaman meliputi penyiraman menggunakan handsprayer dilakukan 2 kali sehari yaitu pada pagi dan sore hari atau disesuaikan dengan keadaan cuaca. Penyiraman dilakukan dengan hati-hati agar bagian bibit yang masi mudah tidak mengalami kerusakan akibat dorongan air. Penyiraman dilakukan secara merata dan dihentikan jika sebagian air telah keluar dari lubang polybag paling bawah. Penyiangan atau pengendalian gulma dilakukan setiap saat gulma tumbuh dengan cara dicabut. Pengendalian hama dan penyakit dilakukan apabila terdapat serangan pada tanaman.

Parameter Pengamatan yang dilakukan pada percobaan ini adalah Tinggi tanaman diukur setiap 3 minggu, pada umur 3, 6, 9 sampai dengan 12 MST pengukuran dilakukan dari pangkal batang sampai titik tumbuh tertinggi menggunakan mistar. Jumlah daun Penghitungan jumlah, Pengukuran diameter batang menggunakan jangka sorong dilakukan dengan cara mengukur setinggi $5 \mathrm{~cm}$ dari permukaan tanah setiap 3 minggu sampai akhir penelitian (12 MST). Panjang akar akar menggunakan mistar dimulai dari pangkal akar sampai dengan ujung akar terpanjang, pengukuran dilakukan diakhir penelitian (12 MST). Berat segar akar dan berangkas Menimbang berat basah akar dan tunas tanaman menggunakan timbangan analitik, dilakukan diakhir penelitian (12 MST). Berat kering akar dan berangkas Menimbang berat akar dan tunas tanaman setelah dilakukan pengeringan dengan menggunakan oven pada suhu $75^{\circ} \mathrm{C}$ selama 24 jam kemudian dilakukan penimbangan menggunakan timbangan analitik. Dilakukan pada akhir penelitian (12 MST)

\section{HASIL DAN PEMBAHASAN}

\section{Tinggi Tanaman dan Jumlah Daun}

Rata-rata tinggi dan jumlah daun tanaman bibit cengkeh berpengaruh sangat nyata pada umur 12 MST. (Tabel 1) dan berpengaruh tidak nyata pada umur 3, 6 dan 9 MST. Sedangkan panjang akar, diameter batang, berat segar dan berat kering berangkasan tidak berpengaruh nyata hingga 12 MST.

Tabel 1. Rata-rata tinggi (cm) dan jumlah daun (Helai) tanaman cengkeh umur 12 MST pada pengaruh kombinasi media tanam.

\begin{tabular}{lcc}
\hline \multicolumn{1}{c}{ Perlakuan } & $\begin{array}{c}\text { Tinggi Tanaman } \\
(\mathbf{c m})\end{array}$ & $\begin{array}{c}\text { Jumlah Daun } \\
(\text { Helai })\end{array}$ \\
\hline P0= Media Tanah (Control) & $16,33 \mathrm{a}$ & $6,11 \mathrm{a}$ \\
P1= Tanah : Pukan 1:1 & $19,87 \mathrm{~d}$ & $6,33 \mathrm{a}$ \\
P2= Tanah : Biochar 1:1 & $17,58 \mathrm{~b}$ & $6,67 \mathrm{ab}$ \\
P3= Tanah : Pukan : Biochar 1:1:1 & $19,89 \mathrm{~d}$ & $8,33 \mathrm{c}$ \\
P4= Tanah : Pukan : Biochar 1:2:1 & $16,82 \mathrm{ab}$ & $6,11 \mathrm{a}$ \\
P5= Tanah : Pukan : Biochar 1:1:2 & $16,80 \mathrm{ab}$ & $7,22 \mathrm{~b}$ \\
P6= Tanah : Pukan : Biochar 1:2:2 & $18,66 \mathrm{c}$ & $7,56 \mathrm{bc}$ \\
\hline BNJ 5\% & $\mathbf{0 , 9 0}$ & $\mathbf{0 , 8 0}$ \\
\hline
\end{tabular}

Keterangan : Angka-angka yang ditandai oleh huruf yang sama pada kolom dan baris yang sama berarti berbeda tidak nyata pada taraf uji BNJ 5\%. 
Hasil penelitian menunjukkan bahwa kombinasi media tanam mempengaruhi tinggi dan jumlah daun bibit cengkeh pada umur 12 MST. Pertambahan tinggi bibit berpengaruh sangat nyata pada penggunaan kombinasi media tanam tanah, pupuk kandang, biochar 1:1:1 (P3). Ratarata peningkatan tinggi bibit cengkeh $21,80 \%$ bila dibandingkan dengan bibit pada media tanam tanpa pemberian biochar. Kombinasi biochar sekam padi, tanah dan pupuk kandang yang seimbang dapat meningkatkan permeabilitas dan perkolasi yang menyebabkan akar tanaman dapat menyerap hara sesuai dengan yang dijelaskan oleh (Sinaga, Arifandi, \& Mandala, 2017) biochar mampu menurunkan berat volume tanah, meningkatkan kapasitas mengikat air. Penelitian ini sejalan dengan (Sasmita, Anas, Anwar, Yahya, \& Djajakirana, 2017) yang menyatakan pemberian biochar bersama bahan organic dapat memberikan pengaruh lebih baik pada bibit tanaman kakao. Biochar dapat meretensi hara (Gani, 2009; Widowati, Utomo, Soehono, \& Guritno, 2011) sehingg lebih tersedia untuk tanaman.

Peningkatan jumlah daun pada bibit cengkeh umur 12 MST didapatkan pada kombinasi tanah, pupuk kandang, biochar dengan perbandingan 1:1:1 (p3) (Tabel 1). Pembentukan tunas pada bibit cengkeh sangat dipengaruhi oleh kondisi lingkungan yang mendukung terbentuknya pucuk daun lebih cepat seperti suhu naungan, dan ketersediaan hara. Penambahan biochar dan pupuk kandang pada mediah tumbuh bibit cengkeh yang dicobakan mampu menyuplai nutrisi dan memberi ruang tumbuh yang optimum untuk pertumbuhan tanaman. seperti yang dilejaskan oleh (Sasmita et al., 2017; Spokas et al., 2011) bahwa biochar yang dikombinasikan dengan pupuk organik lebih efektif. Bahan organik melepas nutrisi seperti N, P, K, S sehingga lebih tersedia bagi tanaman (Sinaga et al., 2017; Spokas et al., 2011; Wahyudi, 2009), selanjutnya biochar meretensi hara tersebut agar tidak mudah tercuci, menguap ataupun masuk kedalam permukaan tanah (Widowati et al., 2011), yang pada akhirnya komposisi tanah, pupuk kandang dan biochar dengan perbadingan 1:1:1 mampu memberi ruang tumbuh yang baik bagi bibit cengkeh sehingga dapat memicu partambahan jumlah daun tanaman cengkeh. Peningkatan jumlah daun merupakan salah satu indikator yang dapat digunakan untuk menentukan pertumbuhan bibit tanaman cengkeh, semakin banyak jumlah daun maka aktivitas fotosintesis yang terjadi pada tanaman tersebut akan semakin meningkat (Gardner, Pearce, \& L.Mitchell, 1991).

\section{Berat Segar dan Berat Kering}

Hasil penelitian menunjukkan bahwa komposisi media tumbuh tidak berbeda nyata terhadap varibel berat segar dan berat kering bibit cengkeh, tetapi komposisi media 1:1:1 memberikan pertambahan berat segar lebih baik dibandingkan perlakuan komposisi media tumbuh lainnya. 


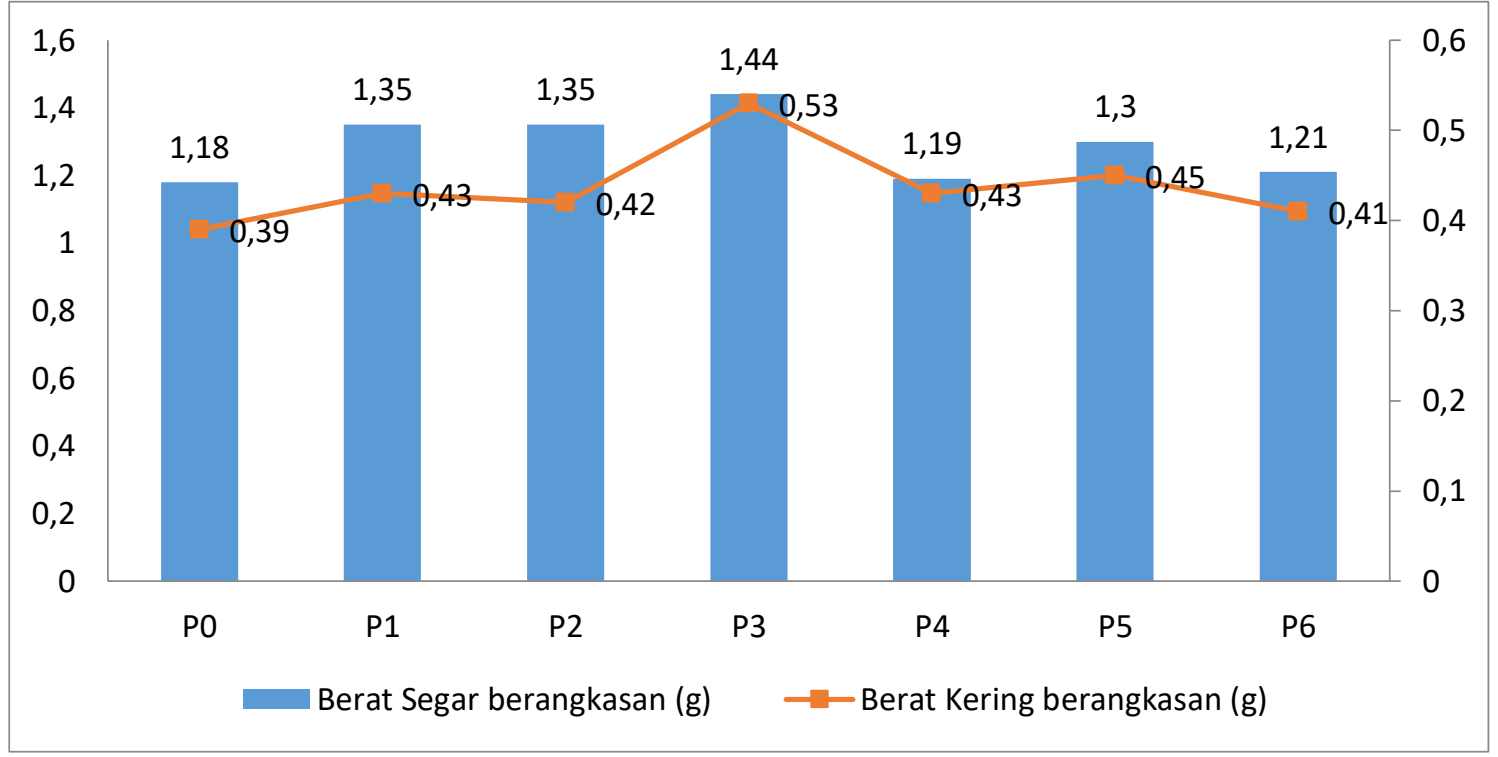

Gambar 3. Grafik hubungan antara berat segar dan berat kering tanaman umur 12 MST

Beberapa hasil penelitian menunjukkan bahwa biochar yang ditambahkan pada media tumbuh belum mampu meningkat biomassa bibit cengkeh, antara lain (Deenik, McClellan, Antal, \& Campbell, 2010) menyatakan bahwa aplikasi biochar yang tinggi dapat menurunkan ketersediaan $\mathrm{N}$ akibat adanya imobilisasi $\mathrm{N}$ yang disebabkan aktifitas mikroba yang tinggi sebagai dampak dari sumplai C labil dari senyawa biochar, selanjutnya (Gale, Sackett, \& Thomas, 2016) biochar tanpa dikombinasikan dengan pupuk organik dapat bersifat toksit bagi tanaman karena biochar mengandung volatile yang dapat meningkatkan respirasi tanah dan menurunkan kadar $\mathrm{N}-\mathrm{NH}_{4}{ }^{+}$

\section{Panjang Akar dan Diameter Batang}

Hasil penelitian menunjukkan bahwa komposisi media tumbuh tidak berbeda nyata terhadap varibel panjang akar dan diameter batang, akan tetapi komposisi media 1:1:1 memberikan pertambahan panjang akar dan diameter lebih baik dibandingkan perlakuan komposisi media tumbuh lainnya (Gambar 4). Penelitian ini berbeda dengan yang dilaporkan (Sasmita et al., 2017) yang bahwa aplikasi biochar dan pupuk organik mampu meningkatkan diameter batang dan bobot kering bibit kakao. Hubungan antara komposisi media dengan panjang akar dan diameter batang disajikan pada gambar 4. Makin besar diameter batang, maka akar bibit makin panjang, hal ini mengindikasikan bahwa semakin besar bibit kebutuhan akan nutrisi juga semakin tinggi, sehingga akar juga ikut berkembang. 


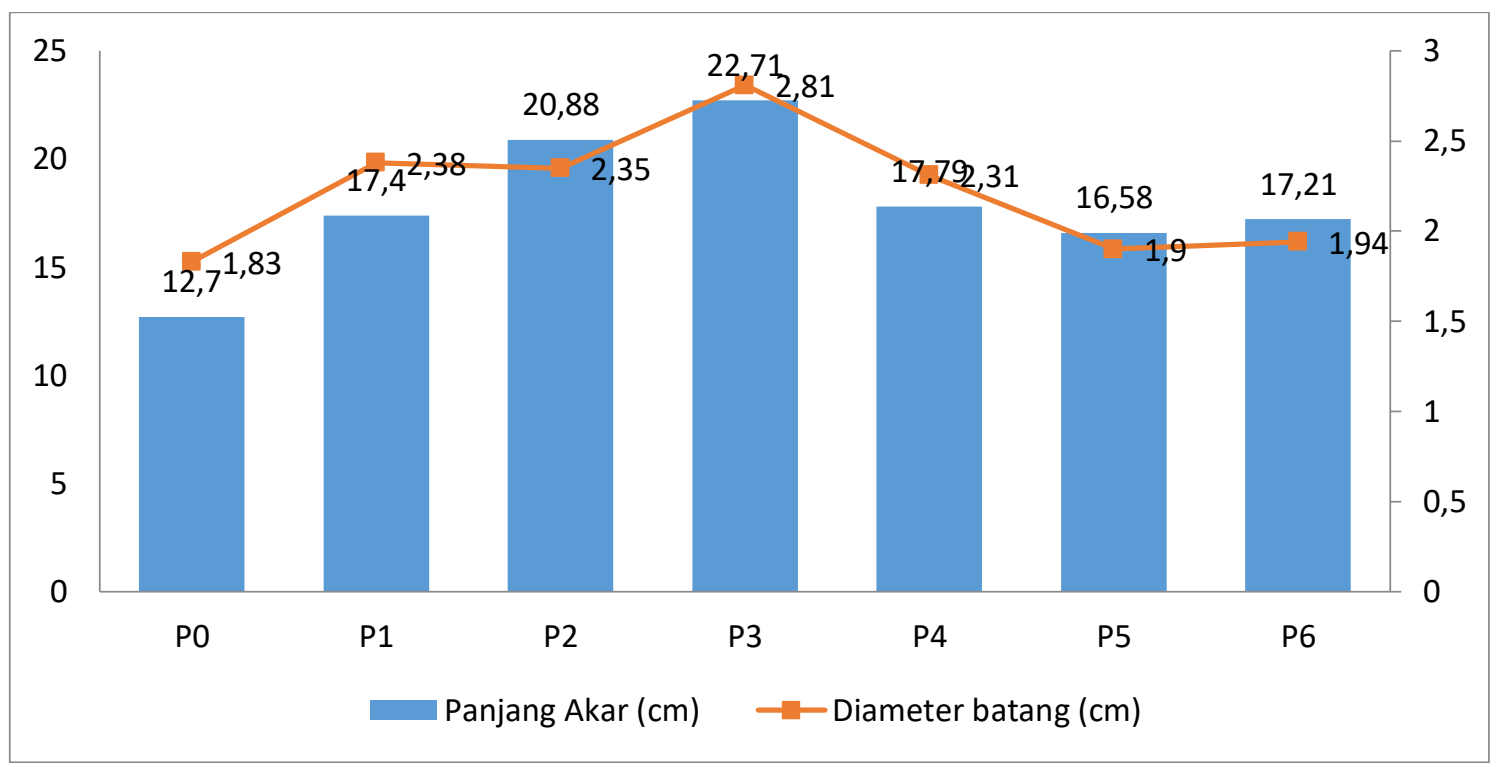

Gambar 4. Hubungan antara panjang akar dan diameter batang umur 12 MST.

Kombinasi pupuk kandang dan biochar pada media tumbuh bersinergi meningkatkan pertumbuhan bibit cengkeh. Pupuk kandang dapat menyuplai N. Biochar dapat menahan unsur nitrogen (Widowati et al., 2011) sehingga nitrogen lebih tersedia untuk pertumbuhan bibit cengkeh. Pertumbuhan bibit yang baik akan berdampak pada tanaman cengkeh. Kombinasi media tumbuh tanah, pupuk kandang sapi dan biochar menyediakan unsur hara di dalam media tanam bibit cengkeh. Pupuk kandang berperan sebagai bahan pembenah tanah yang bermanfaat untuk memperbaiki struktur tanah, meningkatkan daya kation, memacu aktivitas mikroba pendaur hara dan pendekomposisi bahan organik dalam tanah. Sedangkan biochar meretensi hara memperbaikan sifat kimia, dan fisik tanah meningkatkan atau menurunkan $\mathrm{pH}$ tanah (Salawati et al., 2016; Widowati et al., 2011) Bersinergi mendukung pertumbuhan bibit cengkeh.

\section{Kesimpulan}

Berdasarkan hasil penelitian dapat disimpulkan bahwa pada perlakuan kombinasi media tanam yang sesuai untuk pertumbuhan tanaman cengkeh diperoleh pada perlakuan jenis media tanah, pupuk kandang dan biochar dengan perbandingan $1: 1: 1$. Pada kombinasi media tanam tersebut diperoleh tinggi tanaman 19,22 cm, jumlah daun 8,33 (helai), diameter batang 2,81 $\mathrm{mm}$, panjang akar $22,71 \mathrm{~cm}$, berat segar akar dan berangkas 1,44 g serta berat kering akar dan berangkas $0,53 \mathrm{~g}$.

\section{DAFTAR PUSTAKA}

Asai, H., Samson, B. K., Stephan, H. M., Songyikhangsuthor, K., Homma, K., Kiyono, Y., ... Horie, T. (2009). Biochar Amendment Techniques for Upland Rice Production in Northern Laos. 1. Soil Physical Properties, leaf SPAD and Grain Yield. Field Crops Research, 111, 81-84. https://doi.org/10.1016/j.fcr.2008.10.008 
Deenik, J. L., McClellan, T., Antal, M. J., \& Campbell, S. (2010). Charcoal Volatile Matter Content Infl uences Plant Growth and Soil Nitrogen Transformations. Soil Sci.Soc.Ann, 74(4), 1259-1270. https://doi.org/10.2136/sssaj2009.0115

Duong, V. U. T., Khanh, N. M., Nguyen, N. T. H., Phi, N. N., Duc, N. T., \& Xo, D. H. (2017). Impact of Biochar on the Water Holding Capacity and Moisture of Basalt and Grey Soil. Journal of Science Ho Chi Minh City Open University, 7(2), 36-43.

Gale, N. V, Sackett, T. E., \& Thomas, S. C. (2016). Thermal treatment and leaching of biochar alleviates plant growth inhibition from mobile organic compounds. Peerj, $4(\mathrm{e}), 2385-2395$.

Gani, A. (2009). Potensi Arang Hayati “Biochar " Sebagai Komponen Teknologi Perbaikan Produktivitas Lahan Pertanian. Iptek Tanaman Pangan, 4(1), 33-48. Retrieved from http://pangan.litbang.pertanian.go.id/files/03-anischan.pdf

Gao, S., \& DeLuca, T. H. (2016). Influence of Biochar on Soil Nutrient Transformations , Nutrient Leaching, and Crop Yield. Adv. Plants Agric. Res, 4(5), 1-16. https://doi.org/10.15406/apar.2016.04.00150

Gardner, F. P., Pearce, R. B., \& L.Mitchell, R. (1991). Fisiologi Tnaman Budidaya. In UI Press. Indonesia.

Glaser, B., Lehmann, J., \& Zech, W. (2002). Ameliorating Physical and Chemical Properties of Highly Weathered Soils in the Tropics With Charcoal - A review. Biology and Fertility of Soils, 35, 219-230. https://doi.org/10.1007/s00374-0020466-4

Hartatik, W., Wibowo, H., \& Purwani, J. (2015). Aplikasi Biochar dan Tithoganic dalam Peningkatan Produktivitas Kedelai (Glycine max L .) pada Typic Kanhapludults di Lampung Timur. Jurnal Tanah Dan Iklim, 39(1), 51-62. https://doi.org/10.1088/0004-637X/764/1/4

Jha, P., Biswas, A. K., Lakaria, B. L., \& Rao, A. S. (2010). Biochar in Agriculture Prospects and Related Implications. Current Science, 99(9), 1218-1225.

Knowles, O. A., Robinson, B. H., Contangelo, A., \& Clucas, L. (2011). Biochar for the Mitigation of Nitrate Leaching from Soil Amended with Biosolids. Science of the Total Environment, 409, 3206-3210. https://doi.org/10.1016/j.scitotenv.2011.05.011

Laird, D. A., Fleming, P., Davis, D. D., Horton, R., Wang, B. B., Karlen, D. L., ... L.Karlen, D. (2010). Impact of Biochar Amendments on the Quality of a Typical Midwestern Agricultural Soil. Geoderma, 158(3-4), 443-449. https://doi.org/10.1016/j.geoderma.2010.05.013

Lehmann, J. (2007). Bio-Energy in the Black. Frontiers in Ecology and the Environment, 5(7), 381-387. Retrieved from www.frontiersinelogy.org 
Mateus, R., Kantur, D., \& Moy, L. M. (2017). Pemanfaatan Biochar Limbah Pertanian sebagai Pembenah Tanah untuk Perbaikan Kualitas Tanah dan Hasil Jagung di Lahan Kering. Agrotop, 7(2), 99-108. Retrieved from https://ojs.unud.ac.id/index.php/agrotrop/article/view/41166

Nur, M. S. M., Islami, T., Handayanto, E., Nugroho, W. H., \& Utomo, W. H. (2014). The Use of Biochar Fortified Compost on Calcareous Soil of East Nusa Tenggara, Indonesia: 2. Effect on the Yield of Maize (Zea mays L) and Phosphate Absorption. American-Eurasian Journal of Sustainable Agriculture, 8(5), 105-111.

Ogawa, M., Okimori, Y., \& Takahashi, F. (2006). Carbon Sequestration by Carbonization of Biomass and Ferestation: Three Case Studies Mitigation and Adaptation Strategi for Global Change. J. Climate, 11, 421-436. https://doi.org/10.1007/s11027-005-9007-4

Randriani, E., \& Syafaruddin. (2011). Keragaan Pohon Cengkeh Terpilih Tipe Zanzibar dan Siputih Palabuhanratu. Buletin RISTRI, 2(3), 405-410.

Rostaliana, P., Prawito, P., \& Turmudi, E. (2012). Pemanfaatan Biochar Untuk Perbaikan Kualitas Tanah dengan Indikator Tanaman Jagung Hibrida dan padi Gogo pada Sistem Lahan Tebang dan Bakar. Naturalis-Jurnal Penelitian Pengelolaan Sumberdaya Alam Dan Lingkungan, 1(3), 179-188.

Salawati, Basir, M., Kadekoh, I., \& Thaha, A. R. (2016). Potensi Biochar Sekam Padi Terhadap Perubahan $\mathrm{pH}$, KTK, C Organik dan P Tersedia Pada Tanah Sawah Inceptisol. Agroland, 23(2), 101-109.

Santi, L. P., \& Goenadi, D. H. (2010). Pemanfaatan bio-char Sebagai Pembawa Mikroba untuk Pemantap Agregat Tanah Ultisol dari Taman Bogo-Lampung. Menara Perkebunana, 78(2), 52-60.

Sasmita, K. D., Anas, I., Anwar, S., Yahya, S., \& Djajakirana, G. (2017). Pengaruh Pupuk Organik dan Arang Hayati terhadap Kualitas Media Pembibitan dan Pertumbuhan Bibit Cacao. Jurnal Tanaman Industri Dan Penyegar, 4(2), 107-120.

Sinaga, I. A., Arifandi, J. A., \& Mandala, M. (2017). Pengaruh media Tanam dari beberapa Formulasi Biochar Pada Tanah pasiran terhadap Kualitas Bibit Tembakau (Nicotiana tabacum) Besuki Na-Oogst. Agritrop, 15(2), 277-292.

Spokas, K. A., Novak, J. M., Stewart, C. E., Cantrell, K. B., Uchimiya, M., Dusaire, M. G., \& Ro, K. S. (2011). Chemosphere Qualitative analysis of volatile organic compounds on biochar. Pedobiologia, 51(5-6), 359-366. https://doi.org/10.1016/j.chemosphere.2011.06.108

Sujana, I. P. (2014). Rehabilitasi Lahan Tercemar Limbah Garmen Dengan Pemberian Biochar. Pasca Sarjan Udayana, Bali.

Sutono, S., \& Nurida, N. L. (2012). Kemampuan Biochar Memegang Air pada Tanah 
Bertekstur Pasir. Buana Sains, 12(1), 45-52.

Utomo, W. H., \& Islami, T. (2016). Biochar Untuk Pengelolaan Hara Nitrogen. Seminar Nasional Pengelolaan Dan Peningkatan Kualitas Lahan Sub-Optimal Untuk Mendukung Terwujudnya Ketahanan Dan Kedaulatan Pangan Nasional (Pemanfaatan Biochar Untuk Mendukung Pertanian Berlanjut), 1-11. Pontianak 3 Mei 2016.

Wahyudi, I. (2009). Serapan Tanaman Jagung (Zea mays L.) Akibat Pemberian Pupuk Guano dan Pupuk Hijau Lamptoro pada Ultisol Wanga. J. Agroland, 16(4), 265272 .

Widowati, Utomo, W. H., Soehono, L. A., \& Guritno, B. (2011). Effect of Biochar on the Release and Loss of Nitrogen From Urea Fertilization. J. Agric. Food. Tech, 1(7), 127-132.

Yamato, M., Okimori, Y., Wibowo, I. F. F., Anshori, S., Ogawa, M., Okimori, Y., \& Wibowo, I. F. F. (2006). Effects of the Application of Charred Bark of Acacia Mangium on the Yield of Maize, Cowpea and Peanut, and Soil Chemical Properties in South Sumatra, Indonesia. Soil Science and Plant Nutrition, 52(4), 489-495. https://doi.org/10.1111/j.1747-0765.2006.00065.x 